\title{
Elevated blood pressure and illness beliefs: a cross-sectional study of emergency department patients in Jamaica
}

Taneisha T. Wilson 1,2* $\mathbb{D}$, Jean Williams-Johnson ${ }^{3,4}$, Maxine Gossel-Williams ${ }^{5,6}$, Elizabeth M. Goldberg ${ }^{1,2}$, Rainford Wilks ${ }^{6,7}$, Shuvra Dasgupta ${ }^{3,4}$, Georgiana M. Gordon-Strachan ${ }^{6}$, Eric W. Williams ${ }^{3,4}$ and Philip D. Levy ${ }^{8,9}$

\begin{abstract}
Background: Elevated blood pressure (BP) is common among emergency department (ED) patients. While some data exist on the association between ED BP and hypertension (HTN) in the USA, little is known about this relationship in Afro-Caribbean nations. The aim of the study was to evaluate the relationship between elevated systolic BP in the ED and a previous diagnosis of HTN, accounting for potential factors that could contribute to poor HTN control among those with a previous diagnosis: socioeconomic status, health-seeking behavior, underlying HTN illness beliefs, medication adherence, and perceived adherence self-efficacy.

Methods: This was a cross-sectional survey over 6 weeks, from November 19 through December 30, 2014. Those surveyed were non-critically ill or injured adult ED patients ( $\geq 18$ years) presenting to an Afro-Caribbean hospital. Descriptive statistics were derived for study patients as a whole, by HTN history and by presenting BP subgroup (with systolic BP $\geq 140 \mathrm{mmHg}$ considered elevated). Data between groups were compared using chi-square and $t$ tests, where appropriate.
\end{abstract}

Results: A total of 307 patients were included: 145 (47.2\%) had a prior history of HTN, 126 (41.4\%) had elevated BP, and 89 (61.4\%) of those presenting with elevated blood pressure had a previous diagnosis of HTN. Those with less formal education were significantly more likely to present with elevated BP (52.1 vs. 28.8\% for those with some high school and $19.2 \%$ for those with a college education; $p=0.001$ ). Among those with a history of HTN, only 56 (30.9\%) had a normal presenting BP. Those with a history of HTN and normal ED presenting BP were no different from patients with elevated BP when comparing the in duration of HTN, medication compliance, location of usual follow-up care, and HTN-specific illness beliefs.

Conclusions: In this single-center study, two out of every five Jamaican ED patients had elevated presenting BP, the majority of whom had a previous diagnosis of HTN. Among those with a history of HTN, $60 \%$ had an elevated presenting BP. The ED can be an important location to identify patients with chronic disease in need of greater disease-specific education. Further studies should evaluate if brief interventions provided by ED medical staff improve HTN control in this patient population.

Keywords: Hypertension, Illness beliefs, Afro-Caribbean, Medication self-efficacy, Emergency department

\footnotetext{
* Correspondence: taneisha_wilson@brown.edu

${ }^{1}$ Alpert School of Medicine, Brown University, Emergency Medicine, Rhode

Island Hospital, 55 Claverick St. \#2, Providence, RI 02903, USA

${ }^{2}$ University Emergency Medicine Foundation, Kingston, Jamaica

Full list of author information is available at the end of the article
} 


\section{Background}

The Jamaican Health and Lifestyle survey of 2007-2008 estimated that approximately $25 \%$ of the Jamaican population aged 15-74 had high blood pressure (BP); however, only $50 \%$ were aware that they had elevated blood pressure [1-3]. For each $20 \mathrm{mmHg}$ systolic or $10 \mathrm{mmHg}$ diastolic increase in blood pressure (BP) above normal, there is a doubling in risk of cardiovascular, cerebrovascular, and renovascular disease [4-7].

In the USA in 2005, there were 3.3 million high BP-related emergency department (ED) visits [8]. Recent data suggest that the majority of patients with elevated $\mathrm{BP}$ in the ED carry a true diagnosis of hypertension (HTN) $[9,10]$. In the USA and other locations worldwide, the ED often serves as the safety net for persons with chronic diseases such as HTN and may be an important location to help prevent adverse consequences associated with poor BP control $[9,11,12]$.

Anecdotal evidence suggests that there are a significant number of patients who present to Jamaican EDs with elevated BP, those both with and without a prior outpatient diagnosis of HTN. The same may be true for Afro-Caribbean locations, but epidemiological data are lacking. The ED could play an important role in increasing knowledge surrounding how to achieve well-controlled HTN by providing brief education and referral [13]. The ED is often the only source of medical care for those who are underserved [14, 15]. For this reason, emergency medicine clinicians play an important role in improving population BP control [16].

This study was designed to evaluate patients who present to the ED with elevated BP in a representative Afro-Caribbean institution and to evaluate, among patients with known HTN, the relationship between elevated BP and potential contributory factors such as socioeconomic status, health-seeking behavior, and underlying HTN illness beliefs.

\section{Methods}

\section{Setting and subjects}

This cross-sectional survey was conducted over a 6-week period from November 19 through December 30, 2014, at an Afro-Caribbean hospital. The hospital is a large urban teaching hospital located in the Kingston Metropolitan Area. It is affiliated with the University, and the Emergency Medicine division treats approximately 53,000 patients each year.

Patients $\geq 18$ years old who presented to the ED were considered eligible for participation in this study. Those who presented in cardiac arrest, were suffering from trauma requiring immediate operative intervention, or were too ill to provide consent were excluded. This study was approved by the Ethics Committee of the University and all subjects were required to provide informed consent prior to enrollment.

\section{Data collection}

Research assistants administered the survey for approximately $9 \mathrm{~h}$ each day. The ED is divided into three sections: a fast track area, an intermediate care area, and an acute care area. Patients are triaged based on an assessment by a triage nurse and physician. All patients have an initial BP measured by the registered nurse at triage. During the study collection period, research assistants spent $3 \mathrm{~h}$ in each section of the ED. They rotated the starting section each day as follows: day 1: fast track $(3 \mathrm{~h})$, intermediate $(3 \mathrm{~h})$, acute care $(3 \mathrm{~h})$; day 2 : intermediate $(3 \mathrm{~h})$, acute care $(3 \mathrm{~h})$, fast track $(3 \mathrm{~h})$; and day 3 : acute care $(3 \mathrm{~h})$, fast track $(3 \mathrm{~h})$, intermediate $(3 \mathrm{~h})$.

Research assistants approached patients immediately after evaluation by the treating physician. Once consent was obtained, BP, medical history, and socioeconomic information were collected for all patients. For purposes of the study, we defined a triage nurse measured systolic $\mathrm{BP}$ among patients with known HTN, $\geq 140 \mathrm{mmHg}$ as elevated BP. Patients with a known or documented history of HTN, whether they were on antihypertensive medication at the time of enrollment or not, were considered as having a history of HTN. For those with a history of HTN, disease-specific illness beliefs and medication adherence were collected, along with perspectives on medication adherence using a previously validated self-efficacy scale $[17,18]$.

\section{Statistical analysis}

Descriptive statistics were derived for study patients as a whole, by presenting BP subgroups and by HTN history. Data between the groups were compared using chi-square analysis and $t$ tests where appropriate using STATA 14 [19].

\section{Results}

A total of 307 patients were enrolled during the study period, 59.0\% had normal BP. Forty-one percent had an elevated presenting BP while $61.4 \%$ had a previous diagnosis of HTN (Fig. 1; Table 1). Age was significantly different among those presenting with elevated BP $(59.5[ \pm 17.6]$ years vs. $48.9[ \pm 21.6]$ years; $p<0.0001)$. Those with less formal education were significantly more likely to present with elevated BP (52.1 vs. $28.8 \%$ for those with some high school and $19.2 \%$ for those with a college education; $p=0.01)$. Self-reported annual income was not significantly different among those with elevated BP compared to those with normal BP $(\$ 17,746[ \pm 21,648]$ JD vs. $\$ 15,659[ \pm 14,538]$ JD; $p=0.26$ ) (Table 2).

Among those with a history of HTN $(n=145)$, only $38.6 \%$ had a normal BP (Table 3). The mean length of HTN diagnosis was similar among those both with a 


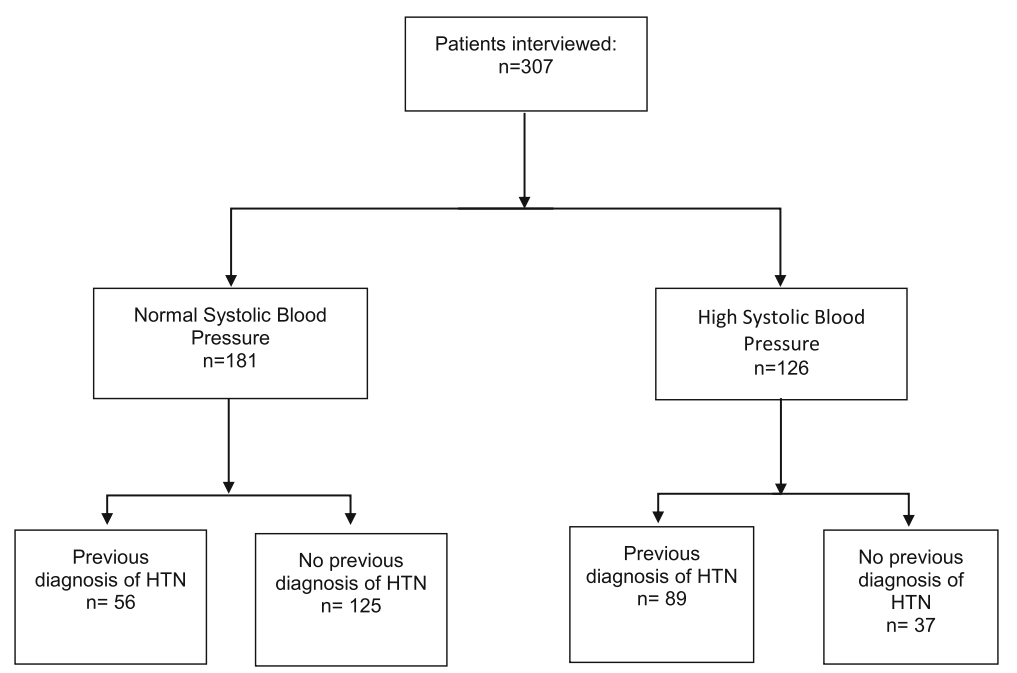

Fig. 1 Study flow diagram. HTN = hypertension

normal BP $(14.7[ \pm 11.2$ years $)$ and without $(13.2[ \pm 12]$ years) $p=0.239$ ). Among those with an elevated presenting BP, anti-hypertensives were prescribed to $62.7 \%$ of the participants compared to $37.3 \%$ of those without elevated BP on presentation. Self-reported medication adherence was high with no differences between groups (77.0\% for those with normal BP vs. $82.2 \%$ in those with elevated BP; $p=0.37$ ). The majority of patients with a previous diagnosis of HTN received their BP management at private physician offices with no difference by group. HTN-specific illness and medication beliefs (Table 4) were similar among patients with a history of HTN who had normal vs. elevated systolic BP. There were also no differences in perceived medication self-efficacy among known hypertensive patients with normal vs. elevated BP (Table 5).

\section{Discussion}

In this convenience sample of patients presenting to the UHWI, approximately 2 out 5 patients had an elevated BP in the emergency department, more than the previously reported 1 out of 5 among American patients primarily of African American descent [9]. Moreover, among those with a previous diagnosis of HTN, BP was elevated in more than $60 \%$. Although these data were derived from a cross-sectional sample in an emergency setting, they suggest that a large number of individuals presenting to the ED have elevated systolic blood pressure with an underlying diagnosis of HTN-more than would be expected

Table 1 Comparing normal vs. elevated triage systolic blood pressure and history of previously diagnosed hypertension

\begin{tabular}{llll}
\hline & Normal SBP, $n(\%)$ & Elevated SBP, $n(\%)$ & Total, $n(\%)$ \\
& $181(59.0)$ & $126(41.0)$ & $307(100.0)$ \\
\hline No history of HTN & $125(77.2)$ & $37(22.8)$ & $167(100.0)$ \\
History of HTN & $56(38.6)$ & $89(61.4)$ & $145(100.0)$ \\
\hline
\end{tabular}

based on other population-level surveys conducted in the general Jamaican population $[2,8]$.

Those with a diagnosis of HTN did not differ in their illness beliefs whether they had normal or elevated presenting BP in the ED. These findings conflict with previous studies reporting negative illness beliefs among those with poorly controlled BPs [20, 21]. Pickett et al. [21] evaluated a cohort of 111 outpatient African American patients and noted that patients with poor disease understanding had poorly controlled BPs. Moreover, we found no difference in reported medication self-efficacy among hypertensives

Table 2 Demographic characteristics of Jamaican ED patients presenting with normal vs. elevated presenting systolic BP

\begin{tabular}{|c|c|c|c|}
\hline & $\begin{array}{l}\text { Normal SBP } \\
N=181(59.0 \%)\end{array}$ & $\begin{array}{l}\text { Elevated SBP } \\
N=126(41.0 \%)\end{array}$ & $p$ value \\
\hline Age, years $( \pm S D)$ & $48.9(21.6)$ & $59.5(17.6)$ & 0.0001 \\
\hline History of HTN, n (\%) & 56 (38.6) & $89(61.4)$ & 0.0001 \\
\hline $\mathrm{SBP}, \mathrm{m}( \pm \mathrm{SD})$ & $119.8(13.9)$ & $167.1(22.0)$ & 0.0001 \\
\hline Income, JD ( \pm SD) & $17,746(21648)$ & 15,659 (14538) & 0.26 \\
\hline Gender, $n$ (\%) & & & 0.26 \\
\hline Women & $96(58.2)$ & $75(64.4)$ & \\
\hline Men & $85(41.9)$ & $51(35.6)$ & \\
\hline Education, $n$ (\%) & & & 0.01 \\
\hline Less than $\mathrm{HS}$ & $64(34.7)$ & $65(52.1)$ & \\
\hline $\mathrm{HS}$ & $76(42.4)$ & $36(28.8)$ & \\
\hline Some college & $40(22.9)$ & $24(19.2)$ & \\
\hline Employment, n (\%) & & & 0.45 \\
\hline Unemployed & $103(57.1)$ & $79(62.9)$ & \\
\hline Employed & $62(33.9)$ & $34(27.1)$ & \\
\hline Retired & $16(0.09)$ & $13(0.1)$ & \\
\hline
\end{tabular}


Table 3 Hypertension care among those with a previous diagnosis of hypertension

\begin{tabular}{|c|c|c|c|}
\hline & $\begin{array}{l}\text { Normal SBP } \\
N=56(38.6)\end{array}$ & $\begin{array}{l}\text { Elevated SBP } n(\%) \\
89(61.4)\end{array}$ & $p$ value \\
\hline Time since HTN diagnosis, years (SD) & $14.7(11.2)$ & $13.2(12.0)$ & 0.239 \\
\hline Prescribed home BP medications, $n(\%)^{\mathrm{a}}$ & $55(37.3)$ & $90(62.7)$ & - \\
\hline BP medication adherence, $n(\%)$ & & & 0.370 \\
\hline No & $12(21.4)$ & $16(17.5)$ & \\
\hline Yes & $42(77.0)$ & $74(82.5)$ & \\
\hline Location of HTN care, $n$ (\%) & & & 0.370 \\
\hline Health center & $9(16.2)$ & $10(11.6)$ & \\
\hline Private doctor & $35(64.5)$ & $50(56.0)$ & \\
\hline Hospital clinic & $5(9.26)$ & $17(19.1)$ & \\
\hline ED & $10(18.5)$ & $13(14.8)$ & \\
\hline
\end{tabular}

SBP systolic blood pressure, HTN hypertension, SD standard deviation, ED emergency department

${ }^{\mathrm{a}}$ All patients reported home anti-hypertensive prescription

with elevated BPs compared to those with normal BPs. A review of the literature reveals a mostly negative correlation, regarding the relationship between disease understanding and medication self-efficacy and the impact on BP control among some populations [22-25].

This disparity between our findings and that previously discussed in the literature may be secondary to this populations' rote knowledge, but not a true understanding of the disease and importance of BP control. Notably, the majority of these studies evaluating illness beliefs were conducted in an outpatient non-emergent setting. Financial insecurity may also account for this incongruence between disease beliefs and medication self-efficacy [26, 27]. Even so, there was no significant discrepancy between incomes among those presenting with elevated BP compared to those presenting with normal BP. However, our findings that education level is associated with BP control underscores the previously identified association between low literacy rates and elevated ED BP [11, 24, 28]. The ED could play an important role in increasing knowledge surrounding how to achieve well-controlled HTN by providing brief education and referral [13].

While this study provides important, previously understudied, epidemiological information about patients who present to the ED with elevated BP in Jamaica, there are several limitations. We used a cross-sectional design with convenience sampling. We attempted to overcome this by capturing patients presenting to the ED during all times and in all areas of the department; however, based on the sampling methodology, our findings might

Table 4 Patient responses about HTN illness beliefs among those with a previous diagnosis of hypertension: comparing those presenting with and without elevated BP

\begin{tabular}{|c|c|c|c|}
\hline & $\begin{array}{l}\text { Normal SBP on presentation } \\
\text { mean }(95 \% \mathrm{CI})\end{array}$ & $\begin{array}{l}\text { Elevated SBP on presentation } \\
\text { mean }(95 \% \mathrm{Cl})\end{array}$ & $p$ value \\
\hline Is an illness that I cannot influence by my behavior & $2.64(2.49-2.78)$ & $2.71(2.51-2.90)$ & 0.56 \\
\hline Is something I go "in" and "out" of & $2.83(2.71-2.95)$ & $2.87(2.67-3.01)$ & 0.72 \\
\hline Is present only when symptoms are present & $2.56(2.42-2.70)$ & $2.56(2.37-2.74)$ & 0.97 \\
\hline Can be cured with therapy & $2.65(2.52-2.79)$ & $2.62(2.43-2.81)$ & 0.74 \\
\hline Requires me to drink fluids especially when thirsty & $2.71(2.58-2.85)$ & $2.72(2.54-2.89)$ & 0.96 \\
\hline Can occur silently (without signs or symptoms) & $2.00(2.00-2.00)$ & $1.98(1.94-2.02)$ & 0.21 \\
\hline Is likely to shorten my life (cause premature death) & $3.21(3.12-3.18)$ & $3.17(3.03-3.30)$ & 0.54 \\
\hline Drugs work best when I have symptoms & $2.61(2.49-2.7))$ & $2.57(2.37-2.76)$ & 0.70 \\
\hline Can get worse by my lifestyle behaviors or actions & $3.09(2.99-3.20)$ & $3.08(2.91-3.24)$ & 0.87 \\
\hline Can be disabling & $3.24(3.14-3.33)$ & $3.09(2.93-3.25)$ & 0.10 \\
\hline Is a threat to my health & $3.24(3.15-3.33)$ & $3.03(2.87-3.20)$ & 0.02 \\
\hline Needs treatment if I feel fine & $3.09(3.00-3.18)$ & $2.94(2.78-3.11)$ & 0.09 \\
\hline May improve with drugs and a lot of time & $3.08(3.01-3.15)$ & $2.98(2.82-3.14)$ & 0.20 \\
\hline Plan of care (drugs, diet...) must be followed forever & $2.99(2.87-3.11)$ & $2.89(2.69-3.08)$ & 0.35 \\
\hline
\end{tabular}

SBP systolic blood pressure, $C l$ confidence interval. Responses ranged from $1=$ strongly disagree, $2=$ disagree, $3=$ agree, $4=$ strongly agree 
Table 5 Perceived medication adherence and medication self-efficacy among patients with a history of HTN who presented with normal vs. elevated systolic BP

\begin{tabular}{|c|c|c|c|}
\hline & $\begin{array}{l}\text { Normal SBP } \\
\text { mean }(95 \% \mathrm{Cl})\end{array}$ & $\begin{array}{l}\text { High SBP } \\
\text { mean }(95 \% \mathrm{Cl})\end{array}$ & $p$ value \\
\hline 1. When you are busy at home & $2.47(2.26-2.69)$ & $2.45(2.17-2.74)$ & 0.92 \\
\hline 2. When you are at work & $4.10(3.69-4.51)$ & $3.69(3.15-2.24)$ & 0.23 \\
\hline 3. When there is no one to remind you & $2.50(2.45-2.67)$ & $2.60(2.28-2.91)$ & 0.45 \\
\hline 4. When you worry about taking them for the rest of your life & $2.46(2.24-2.68)$ & $2.51(2.22-2.79)$ & 0.79 \\
\hline 5. When they cause some side effects & $2.37(2.14-2.60)$ & $2.43(2.14-2.72)$ & 0.72 \\
\hline 6. When they cost a lot of money & $2.46(2.21-2.71)$ & $2.55(2.23-2.86)$ & 0.68 \\
\hline 7. When you come home late from work & $3.85(3.44-4.28)$ & $3.64(2.11-4.16)$ & 0.52 \\
\hline 8. When you do not have any symptoms & $2.55(2.30-2.80)$ & $2.53(2.24-2.82)$ & 0.90 \\
\hline 9. When you are with family members & $2.92(2.21-3.64)$ & $2.62(2.34-2.90)$ & 0.52 \\
\hline 10. When you are in a public place & $2.57(2.35-2.80)$ & $2.62(2.34-2.90)$ & 0.80 \\
\hline 11. When you are afraid of becoming dependent on them & $3.00(2.28-3.71)$ & $2.56(2.28-2.85)$ & 0.36 \\
\hline 12. When you are afraid they may affect your sexual performance & $3.39(3.02-3.76)$ & $3.16(2.70-3.62)$ & 0.44 \\
\hline 13. When the time to take them is between your meals & $2.56(2.32-2.81)$ & $2.53(2.23-2.82)$ & 0.86 \\
\hline 14. When you feel you do not need them & $2.58(2.36-2.81)$ & $2.51(2.22-2.79)$ & 0.68 \\
\hline 15. When you are traveling & $2.53(2.30-2.76)$ & $2.40(2.10-2.70)$ & 0.50 \\
\hline 16. When you take them more than once a day & $2.60(2.37-2.82)$ & $2.55(2.61-2.83)$ & 0.78 \\
\hline 17. If they sometimes make you tired & $2.53(2.30-2.77)$ & $2.45(2.16-2.74)$ & 0.67 \\
\hline 18. When you have other medications to take & $2.58(2.36-2.81)$ & $2.51(2.22-2.80)$ & 0.68 \\
\hline 19. When you feel well & $2.58(2.36-2.81)$ & $2.53(2.34-2.82)$ & 0.76 \\
\hline 20. If they make you want to urinate while away from home & $2.63(2.39-2.87)$ & $2.44(2.14-2.73)$ & 0.31 \\
\hline 21. Get refills for your medications before you run out & $2.48(2.24-2.72)$ & $2.44(2.14-2.73)$ & 0.81 \\
\hline 22. Make taking your medications part of your routine & $2.55(2.32-2.78)$ & $2.58(2.30-2.87)$ & 0.87 \\
\hline 23. Fill your prescriptions whatever they cost & $2.49(2.25-2.73)$ & $2.49(2.20-2.78))$ & 0.99 \\
\hline 24. Always remember to take your BP medications & $2.54(2.31-2.77)$ & $2.55(2.26-2.83)$ & 0.97 \\
\hline 25. Take your BP medications for the rest of your life & $2.54(2.31-2.77)$ & $2.53(2.24-2.81)$ & 0.95 \\
\hline
\end{tabular}

SBP systolic blood pressure, $\mathrm{Cl}$ confidence interval. Responses ranged from: 1 = not at all sure, 2 = somewhat sure, $3=$ very sure

not be generalizable to the overall ED population. We used previously validated survey tools on illness beliefs and medication adherence self-efficacy, but the validation was not done in an Afro-Caribbean population and these scales may not accurately reflect true perspectives of our target population $[17,18]$. Because of interview time constraints, we captured only the illness beliefs of those patients presenting with a previous diagnosis of hypertension. Future studies with larger sample sizes that enroll patients presenting to academic as well as local community hospitals would be of value. Additionally, for simplicity, we did not use a diastolic BP cutoff to define elevated BP; therefore, our estimates of elevated BP frequency may be lower than the true estimate.

\section{Conclusions}

In this single-center study, two of every five Jamaican patients have an elevated BP at ED presentation. Among those with a history of HTN, 60\% had an elevated presenting BP. The ED can be an important location to identify patients with chronic disease in need of greater disease-specific education. Those with lower levels of education may be a particularly important population to target. Future studies should evaluate if brief interventions provided by ED medical staff improve HTN control in this patient population.

\section{Additional file}

Additional file 1: HTN JA patient instrument. (DOCX $110 \mathrm{~kb})$

\section{Abbreviations}

BP: Blood pressure; Cl: Confidence interval; DBP: Diastolic blood pressure; ED: Emergency department; HTN: Hypertension; SBP: Systolic blood pressure; SD: Standard deviation

\section{Funding}

Dr. Wilson received a $\$ 2000$ resident research award from the University Emergency Medicine Foundation (UEMF), Providence RI, in October 2014 which provided housing and printing costs during the duration of this study. 


\section{Availability of data and materials}

Data is available upon request to the corresponding author. Study instrument is located in Additional file 1.

\section{Authors' contributions}

TW was responsible for the study implementation, data collection, statistical analysis, and manuscript preparation. JWJ, MGW, EG, and PL contributed to the conception, design, and implementation of this study as well as draft preparation. SD, RW, GGS, and EWW participated in study design and manuscript preparation. All authors approved the final manuscript.

\section{Ethics approval and consent to participate}

This study was approved by the Ethics Committee of the University of the West Indies, and all subjects were required to provide informed consent prior to enrollment.

\section{Competing interests}

The authors declare that they have no competing interests.

\section{Publisher's Note}

Springer Nature remains neutral with regard to jurisdictional claims in published maps and institutional affiliations.

\begin{abstract}
Author details
'Alpert School of Medicine, Brown University, Emergency Medicine, Rhode Island Hospital, 55 Claverick St. \#2, Providence, RI 02903, USA. ${ }^{2}$ University Emergency Medicine Foundation, Kingston, Jamaica. ${ }^{3}$ University Hospital, University of the West Indies, Mona, Kingston, Jamaica. ${ }^{4}$ The University Hospital of the West Indies, Mona, Kingston, West Indies, Jamaica. ${ }^{5}$ Department of Basic Medical Sciences, University of the West Indies, Mona Kingston, Jamaica. ${ }^{6}$ The University of the West Indies, Mona, Kingston, West Indies, Jamaica. ${ }^{7}$ Tropical Medicine Research Institute, University of the West Indies, Mona, Kingston, Jamaica. ${ }^{8}$ Department of Emergency Medicine, Wayne State University, Detroit, MI, USA. ${ }^{9}$ Emergency Medicine, 6G4 University Health Center, Detroit, MI 48201, USA.
\end{abstract}

Received: 23 August 2017 Accepted: 15 May 2018

Published online: 30 May 2018

\section{References}

1. Mitchell-Fearon K, Waldron N, James K, Laws H, Holder-Nevins D, EldemireShearer D. Hypertension and diabetes prevalence in older persons in Jamaica, 2012. West Indian Med J. 2014;63(5):416-23.

2. Wilks $R$, Younger $N$, Tulloch-Reid M, McFarlane S, Francis D. Jamaica health and lifestyle survey 2007-8. Kingston: Tropical Medicine Research Institute, University of the West Indies, Mona; 2008.

3. Ferguson TS, Francis DK, Tulloch-Reid MK, Younger NO, McFarlane SR, Wilks $\mathrm{RJ}$. An update on the burden of cardiovascular disease risk factors in Jamaica: findings from the Jamaica Health and Lifestyle Survey 2007-2008. West Indian Med J. 2011;60(4):422-8.

4. Cohuet G, Struijker-Boudier H. Mechanisms of target organ damage caused by hypertension: therapeutic potential. Pharmacol Ther. 2006;111(1):81-98.

5. Nadar SK, Tayebjee MH, Messerli F, Lip GY. Target organ damage in hypertension: pathophysiology and implications for drug therapy. Curr Pharm Des. 2006;12(13):1581-92.

6. National High Blood Pressure Education P. The seventh report of the Joint National Committee on prevention, detection, evaluation, and treatment of high blood pressure. Bethesda (MD): National Heart, Lung, and Blood Institute (US); 2004.

7. Viazzi F, Leoncini G, Ratto E, Parodi A, Falqui V, Conti N, et al. Vascular permeability, blood pressure, and organ damage in primary hypertension. Hypertens Res. 2008;31(5):873-9.

8. Nawar EW, Niska RW, Xu J. National hospital ambulatory medical care survey: 2005 emergency department summary. Adv Data. 2007;386:1-32.

9. Karras DJ, Ufberg JW, Heilpern KL, Cienki JJ, Chiang WK, Wald MM, et al. Elevated blood pressure in urban emergency department patients. Acad Emerg Med. 2005;12(9):835-43.

10. Levy PD, Cline D. Asymptomatic hypertension in the emergency department: a matter of critical public health importance. Acad Emerg Med. 2009;16(11):1251-7.

11. Joyner-Grantham J, Mount DL, McCorkle OD, Simmons DR, Ferrario CM, Cline DM. Self-reported influences of hopelessness, health literacy, lifestyle action, and patient inertia on blood pressure control in a hypertensive emergency department population. Am J Med Sci. 2009;338(5):368-72.

12. Zampaglione B, Pascale C, Marchisio M, Cavallo-Perin P. Hypertensive urgencies and emergencies. Prevalence and clinical presentation. Hypertension. 1996;27(1):144-7.

13. Tanabe P, Persell SD, Adams JG, McCormick JC, Martinovich Z, Baker DW. Increased blood pressure in the emergency department: pain, anxiety, or undiagnosed hypertension? Ann Emerg Med. 2008;51(3):221-9.

14. Prendergast HM, Colla J, Del Rios M, Marcucci J, Schulz R, O'Neal T. Playing a role in secondary prevention in the ED: longitudinal study of patients with asymptomatic elevated blood pressures following a brief education intervention: a pilot study. Public Health. 2015;129(5):604-6.

15. Souffront K, Gestal C, Melkus GD, Richardson L. Recognition of asymptomatic hypertension in an urban emergency department: where are we now? Adv Emerg Nurs J. 2016;38(4):320-6.

16. Winters A, Esse T, Bhansali A, Serna O, Mhatre S, Sansgiry S. Physician perception of patient medication adherence in a cohort of medicare advantage plans in Texas. J Manag Care Spec Pharm. 2016;22(3):305-12.

17. Fernandez S, Chaplin W, Schoenthaler AM, Ogedegbe G. Revision and validation of the medication adherence self-efficacy scale (MASES) in hypertensive African Americans. J Behav Med. 2008;31(6):453-62.

18. Ogedegbe G, Mancuso CA, Allegrante JP, Charlson ME. Development and evaluation of a medication adherence self-efficacy scale in hypertensive African-American patients. J Clin Epidemiol. 2003;56(6):520-9.

19. StataCorp. Stata Statistical Software: Release 14. 14th ed. TX: Stata Corp; 2015

20. Hekler EB, Lambert J, Leventhal E, Leventhal H, Jahn E, Contrada RJ. Commonsense illness beliefs, adherence behaviors, and hypertension control among African Americans. J Behav Med. 2008;31(5):391-400.

21. Pickett $S$, Allen W, Franklin M, Peters RM. Illness beliefs in African Americans with hypertension. West J Nurs Res. 2014;36(2):152-70.

22. Ferguson TS, Younger-Coleman NOM, Tulloch-Reid MK, Hambleton IR, Francis DK, Bennett NR, et al. Educational health disparities in cardiovascular disease risk factors: findings from Jamaica health and lifestyle survey 20072008. Front Cardiovasc Med. 2017:4:28.

23. Gleason-Comstock J, Streater A, Ager J, Goodman A, Brody A, Kivell L, et al. Patient education and follow-up as an intervention for hypertensive patients discharged from an emergency department: a randomized control trial study protocol. BMC Emerg Med. 2015;15:38.

24. Grant M, Hezekiah J. Knowledge and beliefs about hypertension among Jamaican female clients. Int J Nurs Stud. 1996;33(1):58-66.

25. Tan AU, Hoffman B, Rosas SE. Patient perception of risk factors associated with chronic kidney disease morbidity and mortality. Ethn Dis. 2010;20(2):106-10.

26. Campbell DJ, Manns BJ, Leblanc P, Hemmelgarn BR, Sanmartin C, King-Shier $K$. Finding resiliency in the face of financial barriers: development of a conceptual framework for people with cardiovascular-related chronic disease. Medicine. 2016;95(49):e5561.

27. Campbell DJ, Manns BJ, Weaver RG, Hemmelgarn BR, King-Shier KM, Sanmartin C. Financial barriers and adverse clinical outcomes among patients with cardiovascular-related chronic diseases: a cohort study. BMC Med. 2017:15(1):33.

28. Horne R, Weinman J. Patients' beliefs about prescribed medicines and their role in adherence to treatment in chronic physical illness. J Psychosom Res. 1999;47(6):555-67.

\section{Submit your manuscript to a SpringerOpen ${ }^{\circ}$ journal and benefit from:}

- Convenient online submission

- Rigorous peer review

- Open access: articles freely available online

- High visibility within the field

- Retaining the copyright to your article

Submit your next manuscript at $>$ springeropen.com 